$\begin{array}{cc}\text { ACADEMIA ROMÂNĂ } & \text { Rev. Roum. Chim., } \\ \text { 2021, 66(3), 303-308 } & \text { Revue Roumaine de Chimie } \\ \text { http://web.icf.ro/rrch/ } & \text { DOI: 10.33224/rrch.2021.66.3.11 }\end{array}$

\title{
PHASE EQUILIBRIA FOR THE CARBON DIOXIDE + CYCLOPENTANE + CYCLOHEXANE SYSTEM AT HIGH PRESSURES
}

\author{
Mihaela IONIȚĂ, ${ }^{\mathrm{a}}$ Sergiu SIMA, ${ }^{\mathrm{a}^{*}}$ Martin CISMONDI $^{\mathrm{b}^{*}}$ and Catinca SECUIANU ${ }^{\mathrm{a}, \mathrm{c}^{*}}$ \\ a Department of Inorganic Chemistry, Physical Chemistry \& Electrochemistry, \\ University Politehnica of Bucharest, S1, 011061, Bucharest, ROUMANIA \\ ${ }^{\mathrm{b}}$ Institute for Research and Development in Process Engineering and Applied Chemistry (IPQA), \\ National University of Córdoba (UNC) - CONICET, Córdoba, Argentina \\ ${ }^{\mathrm{c}}$ Department of Chemical Engineering, Imperial College London, SW7 2AZ, London, UNITED KINGDOM
}

Received October 20, 2020

Isothermal vapor-liquid equilibrium measurements for the ternary mixture carbon dioxide + cyclopentane + cyclohexane at $353.15 \mathrm{~K}$ are reported. Phase equilibrium measurements were made in a high-pressure visual cell with variable volume using a static-analytical method with phases sampling by rapid online sample injectors (ROLSI) coupled to a gas chromatograph (GC) for analysis. The new measured data were modelled with the RK-PR equation of state (EoS) coupled with classical van der Waals (two-parameter conventional mixing rule, 2PCMR).

\section{INTRODUCTION}

Carbon dioxide $\left(\mathrm{CO}_{2}\right)$ is an extremely important product for many applications (separations, supercritical fluid extractions, production of coal liquids, enhanced oil recovery, polymer processing, reactions, nanoparticles formation, fractionations, etc.) and industries (chemical, pharmaceutical, and petrochemical). ${ }^{1,2}$ On the other hand, carbon dioxide is a greenhouse gas and its increasing levels in atmosphere are one of the biggest challenges of the humankind, as they affect the Earth's temperature with serious consequences climate. ${ }^{3}$ Therefore, many efforts are devoted to the reduction of $\mathrm{CO}_{2}$ emissions. ${ }^{2}$ The design and operation of many processes dealing with the $\mathrm{CO}_{2}$ capture and storage (CCS) significantly depend on knowledge about phase behaviour and thermodynamic and/or thermophysical properties of mixtures involved in these processes.

In the last years, our research focused on investigating phase behaviour of systems of interest for carbon capture and storage. Thus, we investigated the phase behaviour of carbon dioxide + different alkanes, ${ }^{4-6}+$ several alcohols, ${ }^{7-11}$ + ethers, ${ }^{12,13}$ or + esthers binary mixtures at high-

*Corresponding authors: catinca.secuianu@upb.ro (C. Secuianu); martin.cismondi@unc.edu.ar (M. Cismondi); sergiu.sima@upb.ro (S. Sima) 
pressures. Here we report phase equilibrium data for the ternary system carbon dioxide (1) + cyclopentane (2) + cyclohexane (3) at $353.15 \mathrm{~K}$ and pressures up to 117 bar. To the best of our knowledge, these are the first data measured for the ternary system $\mathrm{CO}_{2}+$ cyclopentane + cyclohexane. The new data are modelled with the Redlich-Kwong-Peng-Robinson (RK-PR) ${ }^{14-16}$ coupled with classic van der Waals quadratic mixing rules.

\section{EXPERIMENTAL}

\section{Materials}

Carbon dioxide (mass fraction purity $>0.99995)$ was provided by Linde Gaz Romania, Bucharest, Romania, cyclopentane (mass fraction purity $>0.98$ ), and cyclohexane (mass fraction purity $\geq 99.9 \%$ ) were Sigma-Aldrich products, as presented in Table 1. The chemicals were used as supplied, except for drying of the cycloalkanes. Gas chromatographic analyses of the cycloalkanes were also performed, and they confirmed the stated purity by the manufacturer.

\section{Apparatus and Procedure}

The experimental setup was previously described in detail. $^{17-19}$ The main component of the experimental apparatus used in this work is a high-pressure cell equipped with two sapphire windows and variable volume, coupled with a sampling and analyzing system. The sampling system consists of two high-pressure electromechanical sampling valves, namely the rapid on-line sampler injector $\left(\mathrm{ROLSI}^{\mathrm{TM}}\right.$, MINES ParisTech/CEP-TEP - Centre énergétique et procédés, Fontainbleau, France ${ }^{20}$ ). The ROLSI valves are connected to the equilibrium visual cell and to a gas chromatograph (GC) through capillaries. The expansion chamber of the sampler injector is heated with a heating resistance, so the liquid samples are rapidly vaporized. A linear resistor coupled to an Armines/CEP/TEP regulator is used to heat the transferring lines between ROLSI and the GC. The GC (Perichrom) is equipped with a thermal conductivity detector, TCD, and a HP$\mathrm{Plot} / \mathrm{Q}$ column $30 \mathrm{~m}$ long and $0.530 \mathrm{~mm}$ diameter. Helium is the GC carrier gas at a flow rate of $30 \mathrm{~mL} / \mathrm{min}$. The setup is completed with a syringe pump Teledyne ISCO model 500D. As the working procedure is similar as in our previous studies ${ }^{17-}$ ${ }^{19}$, here it will be briefly described. Firstly, the entire internal loop of the apparatus including the equilibrium cell is rinsed several times with carbon dioxide. Then, a vacuum pump is used to evacuate the equilibrium cell. The next step is to charge the cell with the organic substances, which are previously degassed by using a vacuum pump and vigorously stirring. The lighter component (in this case $\mathrm{CO}_{2}$ ) is filled with the syringe pump into equilibrium cell and the pressure is set to the desired value. Then the cell is heated to the experimental temperature.
The mixture in the cell is stirred for a few hours to facilitate the approach to an equilibrium state. Then the stirrer is switched off for about one hour until the coexisting phases are completely separated. Samples of the liquid- and vapour-phases are withdrawn by ROLSI and analyzed with the GC. At least six samples of the liquid phase are normally analyzed at the equilibrium temperature and pressure to check the repeatability. The sample sizes being very small, the equilibrium pressure in the cell remains constant.

The calibration of the TCD for $\mathrm{CO}_{2}$, cyclopentane, and cyclohexane is done by injecting known amounts of each component using gas chromatographic syringes. Calibration data are fitted to quadratic polynomials to obtain the mole number of the component versus chromatographic area. The correlation coefficients of the GC calibration curves were 0.999 for carbon dioxide, 0.999 for cyclopentane, and 0.998 for cyclohexane.

For the phase equilibrium compositions, the relative uncertainty of the mole fractions in the liquid and vapour phases was calculated using the procedure given by Scheidgen. ${ }^{21}$ The average relative uncertainty was $<2 \%$. As usually in the literature, ${ }^{22}$ we report the mole fractions with four decimal places. The uncertainties of the measurements were estimated to be within $0.1 \mathrm{~K}$ for temperature. The platinum temperature probe connected to a digital indicator was calibrated against the calibration system Digital Precision Thermometer with PT 100 sensor (Roumanian Bureau of Legal Metrology). The uncertainty of platinum probe is estimated to be within $\pm 0.1 \mathrm{~K}$ using a similar procedure as described in. ${ }^{23}$ The pressure transducer connected to a digital multimeter was calibrated at $323.2 \mathrm{~K}$ with a precision hydraulic dead-weight tester (model 580C, DH-Budenberg SA, Aubervilliers, France). The uncertainty of the pressures is estimated to be within \pm 0.015 $\mathrm{MPa}$ using a similar procedure as described in, ${ }^{23}$ for a pressure range between 0.5 and $20 \mathrm{MPa}$.

\section{MODELLING}

The ternary system was modelled with a cubic three-parameter equation of state (EoS), namely the generalized Redlich-Kwong-Peng-Robinson (RK-PR) EoS $^{14-16}$ coupled with classic van der Waals quadratic mixing rules.

The generalized RK-PR EoS has the form:

$$
P=\frac{R T}{v-b}-\frac{a_{c}\left(\frac{g}{2+T r}\right)^{k}}{\left(v+\delta_{1} b\right)\left(v+\frac{1-\varepsilon_{1}}{1+\varepsilon_{1}}\right)}
$$

where $T_{\mathrm{r}}$ is the reduced temperature, $k$ is a constant specific for each fluid, calculated from the $a$ value required to match the vapour pressure at $T_{\mathrm{r}}=0.7$, $\delta_{1}$ is the third parameter in the RK-PR EoS.

Table 1

Materials description

\begin{tabular}{llll}
\hline Compound & Source & Purification method & Purity (mass fraction) \\
\hline Carbon dioxide & Linde Gaz Romania & None & $>0.99995$ \\
Cyclopentane & Sigma-Aldrich & None & $>0.980$ \\
Cyclohexane & Sigma-Aldrich & None & $\geq 0.999$ \\
\hline
\end{tabular}


Table 2

Pure compound parameters for the RK-PR EoS ${ }^{5}$

\begin{tabular}{llcccc}
\hline Compound & ID & $\boldsymbol{a}_{\mathbf{C}} \mathbf{b a r} \cdot \mathbf{L}^{2} / \mathbf{m o l}^{\mathbf{2}}$ & $\boldsymbol{b} / \mathbf{L} / \mathbf{m o l}$ & $\boldsymbol{\delta}_{\mathbf{1}}$ & $\boldsymbol{k}$ \\
\hline carbon dioxide & $\mathrm{CO}_{2}$ & 3.7859 & 0.028696 & 1.500000 & 2.28138 \\
cyclopentane & $\mathrm{Cyc5}$ & 18.9220 & 0.070011 & 3.000000 & 1.81752 \\
cyclohexane & $\mathrm{Cyc6}$ & 24.4730 & 0.083709 & 3.000000 & 1.87108 \\
\hline
\end{tabular}

Table 3

Interaction parameters for the RK-PR $\operatorname{EoS}^{5}$

\begin{tabular}{l|l|c|c}
\hline Binary & pair & $\boldsymbol{k}_{\mathrm{ij}}$ & $\boldsymbol{l}_{\mathbf{i j}}$ \\
\hline $\mathrm{CO}_{2}$ & Cyc5 & 0.1142 & -0.0974 \\
$\mathrm{CO}_{2}$ & Cyc6 & 0.1308 & -0.0861 \\
$\mathrm{Cyc5}$ & Cyc6 & 0.0000 & 0.0000 \\
\hline
\end{tabular}

The two-parameter conventional mixing rules are given by:

$$
\begin{aligned}
& a=\Sigma_{i} \Sigma_{f} x_{i} x_{f} a_{i f} \\
& b=\Sigma_{i} \Sigma_{f} x_{i} x_{f} b_{i f}
\end{aligned}
$$

where

$$
\begin{gathered}
a_{i f}=\sqrt{a_{i} a_{j}}\left(1-k_{i j}\right) \\
b_{i f}=\frac{b_{i}+b_{j}}{2}\left(1-l_{i j}\right)
\end{gathered}
$$

This model has been shown ${ }^{16,24-30}$ to be capable of a very accurate representation of the phase behaviour of the more asymmetric alkane mixtures, where typical two-parameter equations like Soave-RedlichKwong (SRK) and Peng-Robinson (PR) fail. The pure compound parameters used in this work for the RK-PR EoS were taken from a previous work dedicated to the binary systems of $\mathrm{CO}_{2}$ with different normal and cycloalkanes ${ }^{5}$ and are given in Table 2. Interaction parameters, adjusted in the same publication based on binary data from the systems involving $\mathrm{CO}_{2}$, are given in Table 3. For simplicity, zero values were used for interaction parameters between the two cycloalkanes.

\section{RESULTS AND DISCUSSION}

Isothermal liquid-vapour equilibrium data were measured at $353.15 \mathrm{~K}$ and pressures between 10.1 and 117 bar with 10 bar increments, as can be seen from Fig. $1 \mathrm{a}$ and $1 \mathrm{~b}$. The $\mathrm{CO}_{2}$ solubility increases with pressure.

The cycloalkanes have similar behaviour in the corresponding binaries with carbon dioxide. ${ }^{5}$ Both binary systems present type II phase behaviour, ${ }^{31,32}$ i.e. one continuous liquid-vapour critical curve stretching between the critical points of pure components and one liquid-liquid critical line intersecting the three-phase liquid-liquid-vapour equilibrium curve in a upper critical endpoint (UCEP), and $\mathrm{CO}_{2}$ is slightly less soluble in cyclohexane than in cyclopentane. However, in the ternary system, the solubility of carbon dioxide in cyclopentane + cyclohexane decreases as the ratios of cyclopentane increased at low to moderate pressures (20-40 bar) reaching a minimum when cyclopentane and cyclohexane have similar concentrations. At higher pressures, the $\mathrm{CO}_{2}$ solubility decreases towards medium concentrations and then slightly increases.

As already explained in the Modelling section, the phase behavior of this ternary system was predicted with the RK-PR/2PCMR model and parameters from a previous work, which did not consider ternary mixtures data. ${ }^{5}$ The comparisons between the model predictions and the experimental data at several pressures are shown in Fig. 2 a-e. It can be observed that with increasing pressure the model is predicting very well the vapour phase composition, while for the liquid phase the $\mathrm{CO}_{2}$ mole fraction is systematically underpredicted by 0.05 approximately.

\section{CONCLUSIONS}

New vapour-liquid equilibrium data were measured for the first time for the carbon dioxide + cyclopentane + cyclohexane ternary mixture using a static analytical method. The system was successfully modelled with the RK-PR model.

Acknowledgements. This work was supported by a grant of Ministry of Research and Innovation, CNCS - UEFISCDI, project number PN-III-P4-ID-PCE-2016-0629, within PNCDI III. 
a

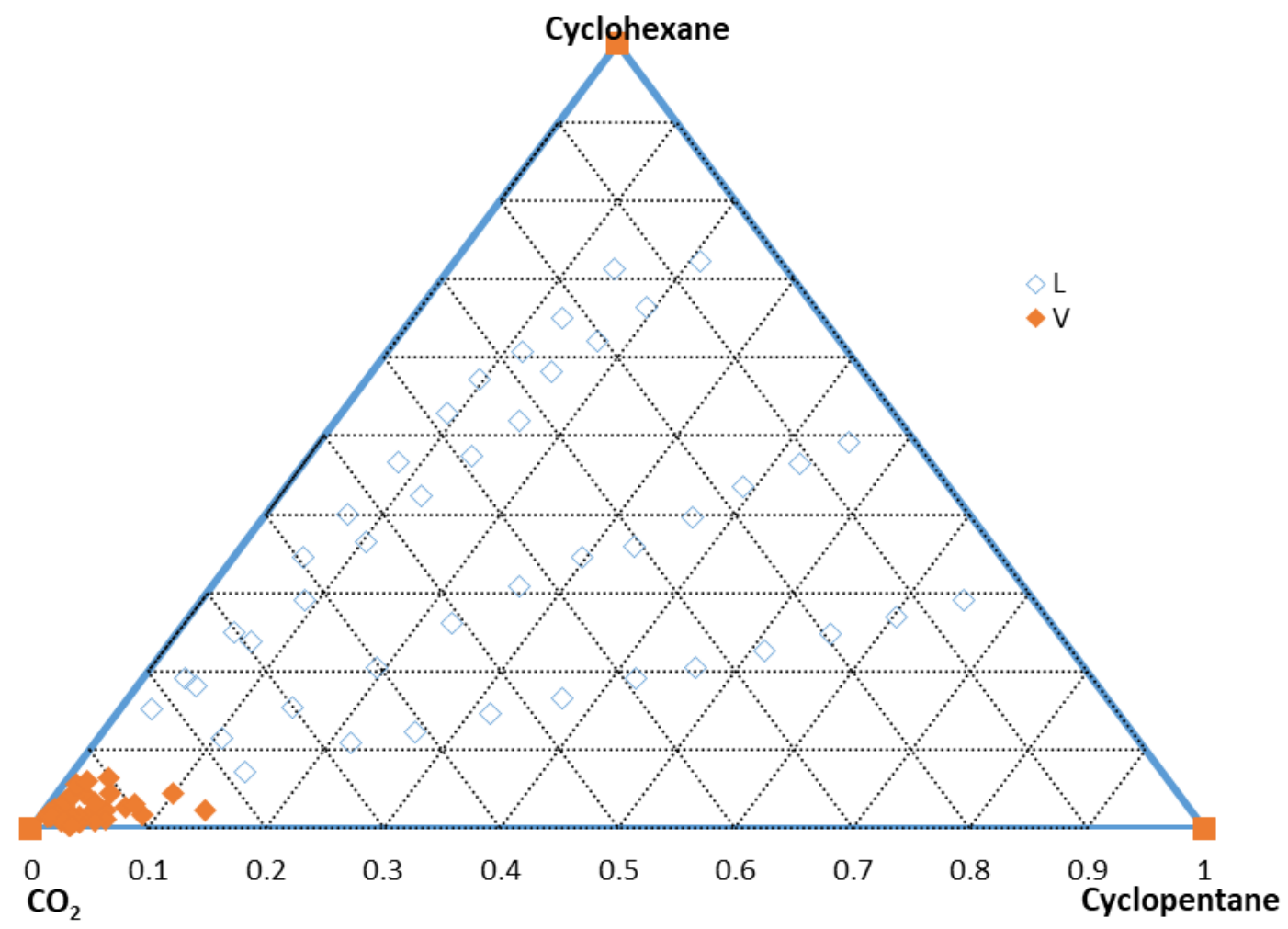

b

\section{Cyclohexane}

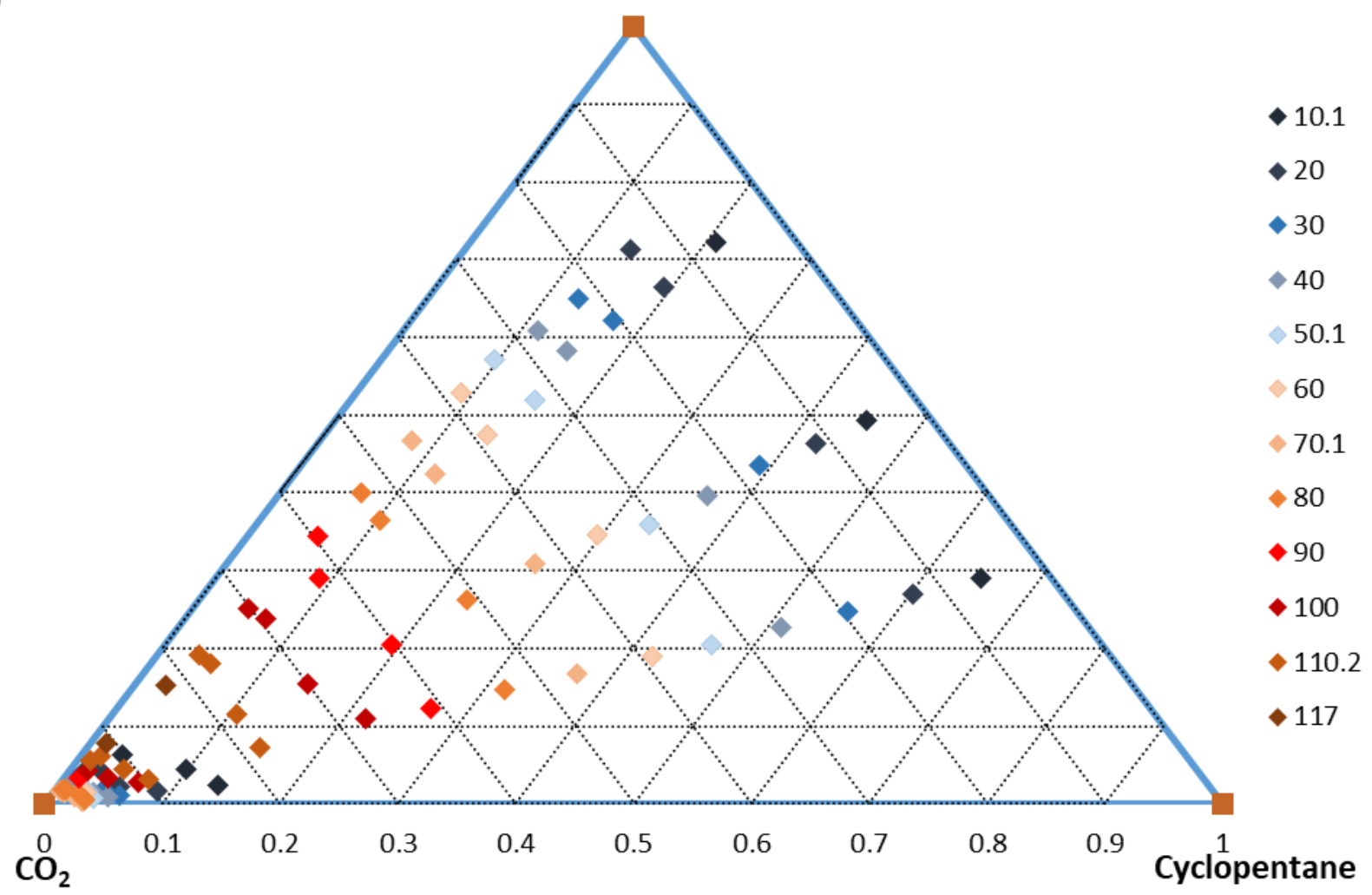

Fig. 1 - Experimental vapour-liquid equilibrium data (a: vapour-liquid phases; b: pressures-compositions) for the carbon dioxide + cyclopentane + cyclohexane ternary system at $T=353.15 \mathrm{~K}$ and pressures between $10-117$ bar. 

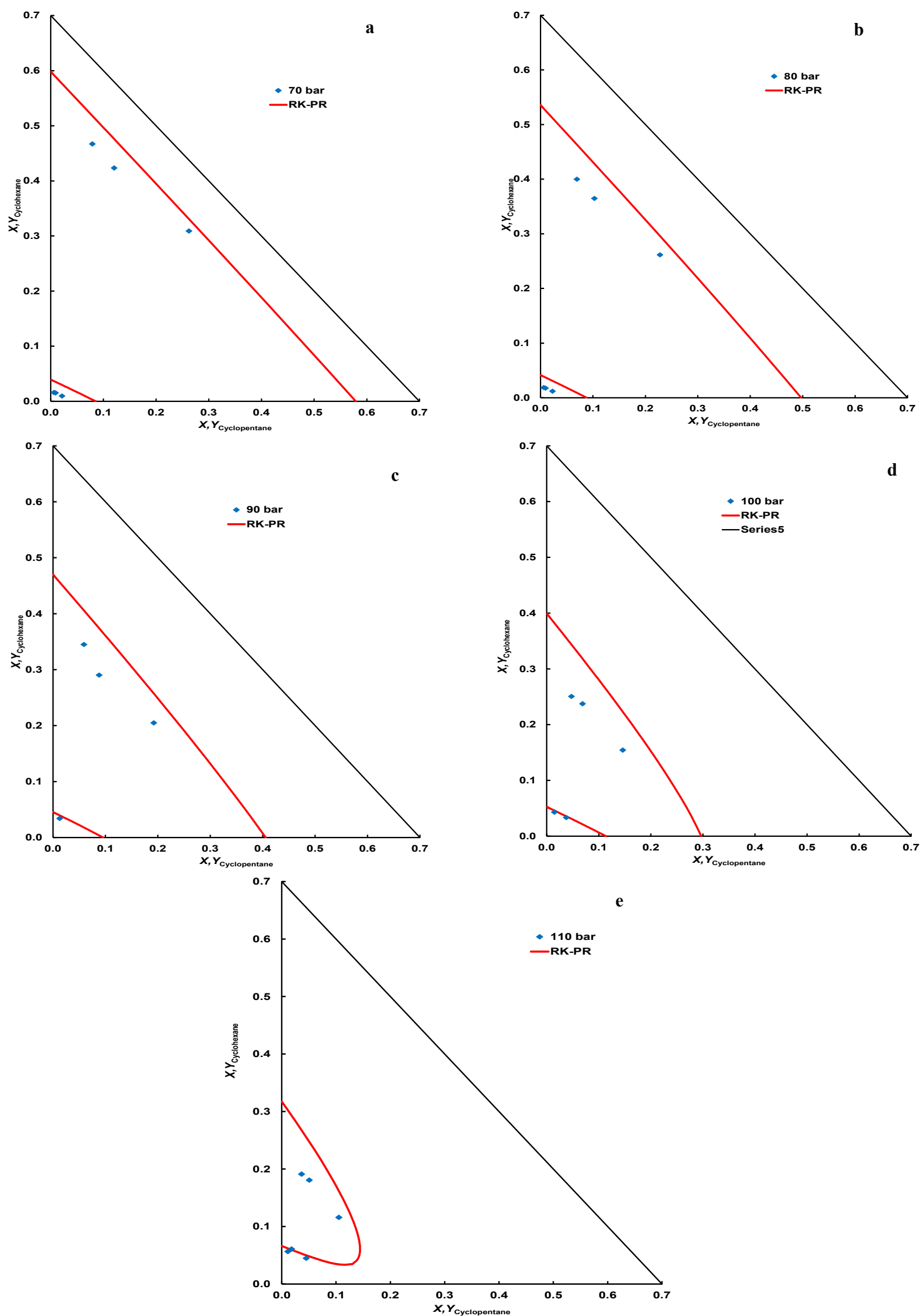

Fig. 2 (a-e) - Comparison of the experimental data with calculation results by RK-PR model for the carbon dioxide + cyclopentane + cyclohexane system at $353.15 \mathrm{~K}$ and various pressures $(70,80,90,100$, and 110 bar). Symbols - experimental data; lines - calculations by RK-PR. 


\section{REFERENCES}

1. J. M. S. Fonseca, R. Dohrn and S. Pepper, Fluid Phase Equilib., 2011, 300, 1

2. S. Pepper, J. M. S. Fonseca and R. Dohrn, Fluid Phase Equilib., 2019, 484, 126.

3. S. D. Kenarsari, D. Yang, G. Jiang, S. Zhang, J. Wang, A. G. Russell, Q. Wei and M. Fan, RSC $A d v$., 2013, 3, 22739 .

4. S. Sima, J. Cruz-Doblas, M. Cismondi and C. Secuianu, Cent. Eur. J. Chem., 2014, 9, 918.

5. S. Sima, J. M. Milanesio, J. I. Ramello, M. Cismondi, C. Secuianu, V. Feroiu and D. Geană, J. Chem. Thermodyn., 2016, 93, 374.

6. A. Crişciu, S. Sima, A. S. Deaconu, A. Chirilă, D. Deaconu, C. Secuianu and V. Feroiu, Rev. Chim.(Bucharest), 2016, 67, 1984.

7. C. Secuianu, S. Ioniță, V. Feroiu and D. Geană, J. Chem. Thermodyn., 2016, 93, 360.

8. C. Secuianu, V. Feroiu and D. Geană, Fluid Phase Equilib., 2016, 428, 62.

9. S. Sima, R. C. Racoviță, C. Dincă, V. Feroiu and C. Secuianu, Univ. Politeh. Buch. Ser. B, 2017, 79, 11.

10. S. Sima, S. Ioniță, C. Secuianu, V. Feroiu and D. Geană, J. Chem. Eng. Data, 2018, 63, 1109.

11. S. Sima, C. Secuianu, V. Feroiu, S. Ioniță and D. Geană, Fluid Phase Equilib., 2020, 510, 1.

12. S. Sima, C. Secuianu and V. Feroiu, Fluid Phase Equilib., 2018, 458, 47.

13. S. Sima, R. C. Racoviță, A. Chirilă, D. Deaconu, V. Feroiu and C. Secuianu, Stud. Univ. Babes-Bolyai Chem., 2019, 64, 129.

14. M. Cismondi and J. Mollerup, Fluid Phase Equilib., 2005, 232, 74.

15. M. Cismondi, E. A. Brignole and J. Mollerup, Fluid Phase Equilib., 2005, 234, 108.

16. M. Cismondi, J. Mollerup and M. S. Zabaloy, J. Supercrit. Fluids, 2010, 55, 671.
17. C. Secuianu, V. Feroiu and D. Geană, J. Chem. Eng. Data, 2003, 48, 1384.

18. C. Secuianu, V. Feroiu and D. Geană, Rev. Chim.Bucharest, 2003, 54, 874.

19. S. Sima, V. Feroiu and D. Geană, J. Chem. Eng. Data, 2011, 56, 5052.

20. P. Guilbot, A. Valtz, H. Legendre and D. Richon, Analusis, 2000, 28, 426.

21. A. Scheidgen, "Fluid phase equilibria of binary and ternary carbon dioxide mixtures with hardly volatile organic substances up to $100 \mathrm{MPa}$. Cosolvency effect, miscibility windows and holes in the critical plane" (in German), Ph.D. Thesis, Ruhr-University Bochum, Bochum, Germany, 1997.

22. R. D. Chirico, M. Frenkel, V. V. Diky, K. N. Marsh (in German) R. C. Wilhoit, J. Chem. Eng. Data, 2003, 48, 1344.

23. S. Sima, V. Feroiu and D. Geană, Fluid Phase Equilib., 2012, 325, 45 .

24. S. B. Rodriguez-Reartes, M. Cismondi, E. Franceschi, M. L. Corazza, J. V. Oliveira and M. S. Zabaloy, J. Supercrit. Fluids, 2009, 50, 193.

25. S. B. Rodriguez-Reartes, M. Cismondi and M. S. Zabaloy, Ind. Eng. Chem. Res., 2011, 50, 3049.

26. M. Cismondi, S. B. Rodriguez-Reartes, J. M. Milanesio and M. S. Zabaloy, Ind. Eng. Chem. Res., 2012, 51, 6232.

27. M. Cismondi Duarte, J. Cruz Doblas, M. J. Gomez and G. F. Montoya, Fluid Phase Equilib., 2015, 403, 49.

28. N. G. Tassin, S. B. Rodriguez Reartes and M. Cismondi, J. Chem. Eng. Data, 2019, 64, 2093.

29. N. G. Tassin N.G., S. B. Rodriguez-Reartes and M. Cismondi, Fluid Phase Equilib., 2020, 522, 112753.

30. N. G. Tassin, S. B. Rodriguez-Reartes, M. S. Zabaloy and M. Cismondi, J. Supercrit. Fluids, 2020, 166, 105028

31. P. H. van Konynenburg and R. L. Scott, Philos. Trans. R. Soc. London, Ser. A, 1980, 298, 495.

32. R. Privat and J. -N. Jaubert, Chem. Eng. Res. Des., 2013, 91, 1807. 